\title{
DIMENSÃO DA PARTICIPAÇÃO EM SAÚDE NO DEBATE \\ INTERNACIONAL DA ATENÇÃO PRIMÁRIA À SAÚDE
}

\author{
THE DIMENSION OF PARTICIPATION IN HEALTH IN THE INTERNATIONAL \\ DEBATE OF PRIMARY HEATH CARE
}

Andréia de Oliveira ${ }^{1}$

\begin{abstract}
RESUMO
Este artigo reflete sobre a trajetória da Atenção Primária à saúde - APS no contexto internacional, com ênfase no debate atribuído à dimensão da participação em saúde e em seus principais marcos históricos, conceitos e abordagens, com destaque para os mecanismos e estratégias de participação social. Conclui que a participação em saúde é inexpressiva na APS e as propostas evidenciadas nos documentos e referências analisadas a direcionam para uma participação de caráter instrumental, voltadas para ações individuais de autocuidado, redução de custos, planejamento e fiscalização, com forte tendência à despolitização e ausência de sentido político-crítico.
\end{abstract}

PALAVRAS-CHAVE: Atenção primária à saúde. Participação. Participação em saúde. Comunidade.

\section{ABSTRACT}

This article reflects on the experience with Primary Health Care - APS in the international context, emphasizing the discussion about the dimension of the participation in health and its major landmarks, concepts and approaches, specially the mechanisms and strategies of social participation. It concludes that participation in health is expressionless in the APS, and the proposals pointed through the analyzed documents and references lead to a participation with instrumental character, focused on individual actions of self-care, cost reduction, monitoring and planning, with a strong tendency to depoliticization and lack of political and critical sense.

KEYWORDS: Primary Health Care. Participation. Participation in Health. Community.

\section{INTRODUÇÃO}

A Atenção Primária à Saúde (APS) tem sido considerada a base para a constituição de um sistema de saúde eficaz, eficiente, qualificado e que preconize o

\footnotetext{
${ }^{1}$ Assistente social; Mestre em Saúde Pública pela Universidade Federal de Santa Catarina (UFSC) e doutora em Serviço Social pela Pontifícia Universidade Católica de São Paulo (PUC-SP); professora adjunta do Departamento de Serviço Social da Universidade de Brasília (UnB). Telefone 6181010161. E-mail: andreiao@unb.br.

Serv. Soc. \& Saúde, Campinas, SP v. 12, n 1 (15), p. 9-30 jan./jun. 2013 ISSN 1676-6806
} 
direito humano à saúde. Apresenta internacionalmente diferentes concepções e perspectivas e, no Brasil, é denominada de Atenção Básica à Saúde.

O presente texto apresenta a trajetória da APS no contexto internacional, com ênfase nos principais marcos históricos e no debate sobre a participação em saúde.

Para tanto, utilizam-se como fontes principais de análise, pela relevância e referência internacional, o estudo de Barbara Starfield, que compara a APS em 12 países industrializados, e foi publicado no Brasil em 2002, pelo Ministério da Saúde (MS), em parceria com a Organização Pan-Americana da Saúde (OPAS); a análise das reformas orientadas pela APS, em países da União Europeia, realizada pelo Observatório Europeu de Sistemas e Políticas de Saúde, a partir de 1990, publicado no Brasil em 2010 pelo MS/OPAS/Organização Mundial da Saúde (OMS); a Declaração de Alma-Ata, de 1978; e o documento de posicionamento da OPAS/OMS de Renovação da Atenção Primária em Saúde nas Américas, de 2008.

No estudo e na análise das referências mencionadas, estabelece-se diálogo com outros autores, entre eles, Giovanella e Mendonça (2008); Conill (2008); Mendes (1996, 2011); Campos (2007); Jara (2006) e Cortês (1996).

A trajetória da APS é marcada por contínuo processo de reconstruções, reflexões, disputas e inspiração para os diferentes sujeitos e segmentos envolvidos, em uma conjuntura de constante crise dos sistemas de saúde, na atualidade.

Crises que vêm marcadas pelo aprofundamento da despolitização das expressões da questão social, no que concerne à saúde, expresso, dentre outras questões, na permanência do modelo biomédico na organização e operacionalização de ações/serviços de saúde, que tendem à impermeabilidade da democratização da política de saúde, acentuada pela hegemonia neoliberal.

Importante se faz refletir sobre diferentes mecanismos e estratégias no processo de construção de políticas de saúde universais, que venham a garantir o direito humano, de forma democrática, integral, equânime e com qualidade. Assim, o enfoque deste ensaio volta-se para a participação em saúde na APS, tendo em vista que esse nível de atenção tem sido considerado base para a constituição de um sistema de qualidade e que preconiza a garantia do direito à saúde.

Num primeiro momento, apresentam-se os antecedentes e principais marcos históricos da atenção primária. Em seguida, os conceitos e as abordagens da APS, com destaque para os mecanismos e as estratégias de participação social, contidos nos estudos mencionados, e, por último, os valores, princípios e elementos estruturais e Serv. Soc. \& Saúde, Campinas, SP v. 12, n 1 (15), p. 9-30 jan./jun. 2013 ISSN 16766806 
funcionais referendados no documento de Renovação da APS nas Américas, da OPAS/OMS, e o enfoque atribuído à participação social, no âmbito da APS.

\section{Atenção Primária à Saúde: Antecedentes Históricos e Principais Marcos}

Os primeiros cuidados ambulatoriais ocorrem, de forma mais coletiva, a partir do século XIII, por meio de corporações de artesãos e dispensários, as primeiras unidades de saúde ambulatoriais. Surgem por iniciativa de um médico francês, no século XVII, em Paris/França, com objetivos filantrópicos e, posteriormente, é seguido por escolas de medicina, que passam a oferecer consultas gratuitas como campo de treinamento para alunos (ROEMER, 1985, apud GIOVANELLA; MENDONÇA, 2008).

Na Inglaterra, os dispensários são criados a partir do século XVII e, nos Estados Unidos da América (EUA), no século XVIII. Dependentes de doações, ofereciam atendimento ambulatorial, aos pobres urbanos, por médicos ou farmacêuticos, com pequenas cirurgias, aplicação de vacina contra varíola, distribuição de medicamentos e extração de dentes. Somente no início do século XX são substituídos por centros de saúde (ROEMER, 1985, apud GIOVANELLA; MENDONÇA, 2008).

Já a propagação de proposta formal do governo de organizar um primeiro nível de atenção é atribuída ao Relatório de Dawson, preparado na Grã-Bretanha, em 1920, que propõe um sistema de serviços de saúde, tendo como referência três níveis principais: centros de saúde primários, centros de saúde secundários; e hospitais-escola (STARFIELD, 2002). Formulação, segundo a referida autora, fundamenta o conceito de regionalização, base da reorganização dos serviços de saúde em muitos países.

As propostas do Relatório de Dawson contrapõem-se às recomendações de Abraham Flexner, derivadas da avaliação do ensino médico nos EUA, em 1910, entre elas, da centralidade na atenção médica individual, com pouca ênfase na prevenção e promoção em saúde, na valorização do hospital na atenção e na atividade de ensino, com destaque nas especialidades (PAIM, 2008).

No entanto, apesar da relevância das propostas do Relatório de Dawson, sua implantação não ocorre imediatamente. São necessários mais de 50 anos para retomar 
alguns dos pressupostos e fundamentar iniciativas de organização dos sistemas de saúde.

Na década de 1960, disseminam-se os centros de saúde, quando unidades são construídas na Inglaterra e médicos generalistas passam a realizar consultas em conjunto com outros profissionais, como enfermeiras, visitadoras domiciliares e assistentes sociais (GIOVANELLA; MENDONÇA, 2008).

Na mesma década, diante da crise decorrente da expansão de serviços cada vez mais especializados, conjuntura de crise econômica e do modo de acumulação instalado nos países centrais, ressurge, nos EUA, um movimento em favor da medicina ou saúde comunitária, com duas vertentes principais, segundo Conill (2008, p. 8): “De um lado os departamentos de medicina social e preventiva de centros universitários e, de outro, o contexto da 'guerra à pobreza' desencadeada pelo governo federal”.

Nos anos 1970, o debate sobre a APS intensifica-se internacional e nacionalmente, principalmente após a Conferência Internacional sobre Atenção Primária em Saúde ${ }^{2}$, organizada pela OMS e o Fundo das Nações Unidas para a Infância (Unicef), realizada em Alma-Ata, cidade do Cazaquistão, em 1978.

O evento ocorre num contexto de crise estrutural do capital, principalmente a partir de 1970, que rompe gradativamente com o pacto dos anos de crescimento, de pleno emprego (keynisianismo/fordismo) e desenho social democrata para as políticas sociais, de modo que fornece as bases para fortalecer ideias neoliberais, sobretudo relacionadas à liberalização dos mercados nacional e internacional, à redução substancial do tamanho do Estado, e à privatização das empresas estatais e dos serviços públicos (ANDERSON, 1995).

A regulamentação social democrata que sustentou o Estado de Bem-Estar Social vem se subordinando de maneira crescente à ordem do capital, sob orientação neoliberal. Sob o signo da crise monetária internacional, do declínio da atividade econômica e do endividamento público, o capital financeiro passa, a partir de então, a operar o comando do processo de acumulação impulsionado pelos organismos multilaterais, e "mediante inéditos processos sociais, envolve a economia e a sociedade, a política e a cultura, vincando profundamente as formas de sociabilidade e o jogo das forças sociais” (IAMAMOTO, 2008, p. 107).

\footnotetext{
${ }^{2}$ Antecede a conferência de Alma-Ata, período de questionamentos dos modelos verticais, seletivos e descontextualizados de intervenção da OMS no combate às endemias nos países em desenvolvimento $\mathrm{e}$ também se faziam presentes questionamentos, principalmente desde o final da década de 1960, ao modelo biomédico de atenção à saúde.

Serv. Soc. \& Saúde, Campinas, SP v. 12, n 1 (15), p. 9-30 jan.jun. 2013 ISSN 1676-6806
} 
O declínio da atividade econômica e o endividamento público diminuem a arrecadação dos governos e desencadeiam forte pressão pela redução de despesas com políticas sociais e racionalização das estruturas burocráticas estatais, no Estado de BemEstar Social, por meio de reformas que "implicaram na criação de mecanismos participatórios, os quais poderiam, ao mesmo tempo, exercer pressão e servir como fiscalizadores sobre uma burocracia resistente às mudanças" (CORTÊS, 1996, p. 31).

Para a autora, nesse contexto, e sob distintas orientações políticas, são instituídas diferentes formas de participação. Os governos conservadores ${ }^{3}$, com base na perspectiva da privatização dos serviços, veiculam a ideia de participação do consumidor individual, na lógica do mercado, "dado o seu ceticismo em relação à legitimidade das lideranças das entidades que representavam os interesses de diversos setores" (CORTÊS, 1996, p. 32). Já os governos socialdemocratas ${ }^{4}$ enfatizam a necessidade de reforma das organizações públicas, porém, mantendo a noção de provisão pública de bens e serviços, sem o uso da estratégia centrada no mercado, e propõem "aumentar as oportunidades para que cidadãos ou usuários expressassem suas opiniões, ampliando o direito dos participantes em manifestar oposição e propor alternativas” (CORTÊS, 1996, p. 32).

No percurso da década de 1970, segundo a autora, em vários países, como EUA, Canadá, Grã-Bretanha, Itália e Alemanha, são criados e institucionalizados mecanismos participatórios em resposta às demandas de participação direta dos cidadãos no processo político. "A natureza dessa participação variava desde a mera consulta ou advocacia dos interesses de consumidores e de usuários até o envolvimento ativo destes participantes em comitês, comissões e conselhos” (CORTÊS, 1996, p. 32).

Na área da saúde, a autora cita como exemplo as experiências dos EUA: participação de cidadãos em boards de Centros Vicinais de Saúde, ao final dos anos 60 e durante a década de 1970, os centros comunitários de saúde mental e os serviços de ouvidoria em programas de saúde; a experiência na Grã-Bretanha, em 1974, na presença de membros não executivos das autoridades de saúde e dos conselhos comunitários de

\footnotetext{
${ }^{3}$ Essa primeira estratégia, para Cortês (1996), objetivava a privatização e propunha a independência cultural estimulada pelo Estado de Bem-Estar Social, que criara "indivíduos preguiçosos", proposta apoiada por grupos que representavam o capital.

${ }^{4}$ A segunda estratégia, defendida pelos sindicatos, visava à manutenção dos ideais igualitários de equidade e justiça social (CORTÊS, 1996).

Serv. Soc. \& Saúde, Campinas, SP v. 12, n 1 (15), p. 9-30 jan./jun. 2013 ISSN 1676-6806
} 
saúde; e a canadense, em Quebec, de 1970 a 1972, com a criação da prerrogativa legal, que estabelecia a participação dos cidadãos em boards dos hospitais e casas de saúde e nas agências de assistência social. (CORTÊS, 1996)

Todavia, Cortês (1996) enfatiza que a criação de mecanismos participatórios pode ser associada às pressões decorrentes da desilusão com os mecanismos de participação tradicionais das democracias liberais, da emergência de novos movimentos sociais, da crise econômica mundial com seus desdobramentos na reforma das instituições públicas, como também ao "estímulo das agências internacionais à participação da comunidade ou popular, durante os anos 70” (CORTÊS, 1996, p. 33).

A autora supracitada refere-se à Declaração dos Cuidados Primários de Saúde, como exemplo da influência exercida pelos organismos internacionais, na origem de processos participativos na área da saúde.

A Conferência de Alma-Ata ${ }^{5}$ é referência internacional e representa um marco nos debates acerca das políticas de saúde no mundo e do direito humano à saúde. A atenção primária foi concebida como:

Cuidados essenciais de saúde baseados em métodos e tecnologias práticas, cientificamente bem fundamentadas e socialmente aceitáveis, colocadas ao alcance universal de indivíduos e famílias da comunidade, mediante sua plena participação e a um custo que a comunidade e o país possam manter em cada fase de seu desenvolvimento, no espírito de autoconfiança e automedicação. Fazem parte integrante tanto do sistema de saúde do país, do qual constitui a função central e o foco principal, quanto do desenvolvimento social e econômico global da comunidade. Representam o primeiro nível de contato dos indivíduos, da família e da comunidade com o sistema nacional de saúde, pelo qual os cuidados de saúde são levados o mais proximamente possível aos lugares onde pessoas vivem e trabalham, e constituem o primeiro elemento de um continuado processo de assistência à saúde. (CONFERÊNCIA INTERNACIONAL SOBRE CUIDADOS PRIMÁRIOS DE SAÚDE, 1978).

A APS representa o primeiro nível de contato com o sistema de saúde, mas não se restringe a esse nível; integra o processo permanente de assistência e eixo de reorganização dos sistemas de saúde, que inclui a prevenção, promoção, cura, reabilitação e participação comunitária.

Starfiel (2002), ao analisar a concepção de APS preconizada em Alma-Ata,

\footnotetext{
${ }^{5}$ A Conferência de Alma-Ata contou com a participação de 134 governos, com mais de 3 mil delegados, mas o Brasil não se fez representar (GIOVANELLA; MENDONÇA, 2008).

Serv. Soc. \& Saúde, Campinas, SP v. 12, n 1 (15), p. 9-30 jan./jun. 2013 ISSN 1676-6806
} 
evidencia três momentos nos quais a palavra "comunidade" aparece ${ }^{6}$, de modo que, para a autora, há distinção entre a atenção prestada a indivíduos ou famílias e a atenção prestada à comunidade.

A Declaração de Alma-Ata reafirma o direito à saúde e a responsabilização dos governos pela saúde de seus povos. Apresenta concepção abrangente de APS e destaca a participação, como "direito e dever dos povos de participar individual e coletivamente no planejamento e na execução de seus cuidados de saúde" (CONFERÊNCIA INTERNACIONAL SOBRE CUIDADOS PRIMÁRIOS DE SAÚDE, 1978). Ainda coloca que os cuidados primários em saúde:

Requerem e promovem a máxima autoconfiança e participação comunitária e individual no planejamento, organização, operação e controle dos cuidados primários de saúde, fazendo o mais pleno uso possível de recursos disponíveis, locais, nacionais e outros, e para esse fim desenvolvem, através da educação apropriada, a capacidade de participação das comunidades. (CONFERÊNCIA INTERNACIONAL SOBRE CUIDADOS PRIMÁRIOS DE SAÚDE, 1978).

O consenso em torno dessa base conceitual destaca elementos que a OMS está empenhada em difundir, nesse momento, implementados em diversos países e de diferentes maneiras (CONILL, 2008): integração dos serviços locais num sistema nacional, participação, necessidade de ações intersetoriais e a relação da saúde com o desenvolvimento econômico e o social.

Para Conill (2008), o conteúdo proposto articula-se em torno de dois polos principais, expressando respostas a necessidades de ordens econômica, política e social, como também demandas oriundas dos movimentos sociais e setoriais desse contexto, a saber: polo tecnocrático, propondo a incorporação de medidas inovadoras e de racionalização das práticas; e, outro, participativo, associado à democratização dos serviços, com ampliação da equipe, inserção de agentes da comunidade, acesso e controle social.

\footnotetext{
6 “[...] a um custo que a comunidade possa manter [...] como parte integral [...] do desenvolvimento global econômico e social da comunidade [...] primeiro nível de contato de indivíduos, família e comunidade com o sistema nacional de saúde" (CONFERÊNCIA INTERNACIONAL SOBRE CUIDADOS PRIMÁRIOS DE SAÚDE, 1978, p. 1).

Serv. Soc. \& Saúde, Campinas, SP v. 12, n 1 (15), p. 9-30 jan.jun. 2013 ISSN 1676-6806
} 
Reafirmam-se a importância, o significado e a amplitude das propostas, do pressuposto e dos desdobramentos, desencadeados pela Conferência de Alma-Ata, principalmente na conjuntura daquele momento. No entanto, a falta de posicionamento mais contundente com relação à ordem econômica vigente, sem considerar o entrelaçamento entre política social e política econômica, encontra confortável acolhida por parte das agências burocráticas estatais, dos organismos multilaterais, como o Banco Mundial, o Fundo Monetário Internacional (FMI), que, sob a perspectiva neoliberal, utilizam-se de conceitos e os reconstroem para o alcance e fins dos interesses do capital, a exemplo das definições e orientação quanto aos gastos sociais públicos em países empobrecidos, como os da América Latina.

A perspectiva participacionista, contida na Declaração de Alma-Ata, expressa um sentido de execução e colaboração para o alcance da eficiência nos cuidados em saúde, que, despojado de sentido sociocrítico, fortalece a participação reconfigurada e exaltada pelos princípios neoliberais de desresponsabilização estatal e transferência das responsabilidades para a sociedade civil, com base em um discurso de participação solidária.

Ela recomendava a implementação de políticas de cuidados primários de saúde, que estimulariam o autocuidado e autonomia das comunidades (HOLLNSTEINER, 1982, apud CORTÊS, 1996, p. 34). Acima de tudo, ela defendia a mobilização das comunidades locais para que elas assumissem responsabilidade por sua própria saúde (MIDGLEY, 1986, apud CORTÊS, 1996, p. 34-35).

Os traços preconizados em Alma-Ata, que apontavam para uma perspectiva mais abrangente da APS, foram fortemente criticados por agências internacionais, entre elas, a Fundação Rockefeller, que, no ano seguinte à Declaração de Alma-Ata, em 1979, provê, com o Banco Mundial, a Fundação Ford, o Centro Internacional para a Pesquisa e o Desenvolvimento, e a Agência Internacional para o Desenvolvimento, uma reunião na Itália, quando se discute uma noção seletiva de APS, como estratégia para o controle de doenças nos países em desenvolvimento (GIOVANELLA; MENDONÇA, 2008).

Tal perspectiva, conforme as autoras, fundamenta intervenções de baixo custo para combater as principais doenças, em países pobres. Na década de 1980, essa concepção seletiva e restrita da APS passa a ser hegemônica para diversas agências internacionais, a exemplo do Banco Mundial, atualmente conhecida como atenção primária seletiva, discussão que faremos na sequência.

Serv. Soc. \& Saúde, Campinas, SP v. 12, n 1 (15), p. 9-30 jan./jun. 2013 ISSN 1676-6806 


\section{APS no Contexto Internacional: Interpretações, Conceitos e Abordagens}

No Relatório Dawson, em 1920, estão as origens da APS e, a partir de 1978, pós-Conferência de Alma-Ata, concretiza-se a sua institucionalização nos sistemas de saúde. Desde então, é compreendida, interpretada e operacionalizada de diferentes maneiras e sob variadas terminologias. É comum, na bibliografia internacional, o uso da expressão Atenção Primária à Saúde, em lugar de Atenção Básica em Saúde, como denominada aqui no Brasil; embora certos autores, a exemplo de Mendes (2011), e documentos de organismos governamentais, como o Conselho Nacional de Secretários de Saúde (CONASS) ${ }^{7}$ e do próprio Ministério da Saúde ${ }^{8}$, tenham utilizado a terminologia internacionalmente reconhecida de APS.

Contudo, mais do que a terminologia adotada, importam as diferentes concepções, abordagens e práticas incorporadas, que reforçam ou se contrapõem a uma perspectiva ampliada/abrangente de APS. De maneira geral, identificam-se três interpretações principais: Giovanella e Mendonça (2008); Mendes (1996); Organização Pan-Americana da Saúde (2011):

1) Compreendida como estratégia de reordenamento do setor da saúde e como modelo assistencial.

2) Como estratégia de organização e reordenamento do primeiro nível de atenção do sistema de saúde, ou seja, de organizar e operacionalizar a porta de entrada do sistema.

3) Concebida como programa focalizado e seletivo, destinado a populações e regiões pobres, com cesta restrita de serviços, baixa densidade tecnológica e baixos custos.

Conill (2008, p. 2), ao realizar estudo sobre a trajetória histórico-conceitual da APS como política de reorganização do modelo assistencial, identifica duas concepções predominantes do conceito: “[...] a de cuidados ambulatoriais na porta de entrada ou a

\footnotetext{
${ }^{7}$ BRASIL. Conselho Nacional de Secretários de Saúde. Atenção primária e promoção da saúde. Brasília: Conass, 2011. Coleção para Entender a Gestão do SUS, v. 3.

${ }^{8}$ BRASIL. Ministério da saúde. Diretrizes do NASF: núcleo de apoio à saúde da família. Série A. Normas e Manuais Técnicos. Caderno de Atenção Básica, n. 27, 2010.

Serv. Soc. \& Saúde, Campinas, SP v. 12, n 1 (15), p. 9-30 jan./jun. 2013 ISSN 1676-6806
} 
de uma política de reorganização do modelo assistencial, quer seja sob forma seletiva ou ampliada”.

No estudo da pesquisadora norte-americana Barbara Starfield (2002), a APS trata os problemas mais comuns na comunidade, oferecendo serviços de prevenção, cura e reabilitação para elevar ao máximo a saúde e o bem-estar. Integra a atenção em que ocorre mais de um problema de saúde e tem influência nas respostas das pessoas a seus problemas de saúde. É a atenção que organiza, racionaliza o uso dos recursos, tanto básicos como especializados, direcionados para a promoção, manutenção e melhoria da saúde.

A autora desenvolve uma abordagem para caracterizar a APS nos países industrializados, definindo quatro atributos exclusivos da atenção primária e três atributos derivativos. Como atributos exclusivos, identifica: a) Atenção ao primeiro contato: acessibilidade e uso do serviço sempre que o usuário necessitar e para acompanhamento rotineiro da sua saúde; b) Longitudinalidade: pressupõe a existência de uma atenção longitudinal do usuário, com continuidade ao longo do tempo e fortes laços e vínculos interpessoais destes e dos profissionais de saúde; c) Integralidade: implica o acesso a todos os tipos de serviços de atenção à saúde, preventivos e curativos, na própria unidade ou por meio de encaminhamento para serviços secundários, a depender das necessidades existentes; d) Coordenação: refere-se à continuidade do tratamento no próprio serviço e com outros serviços fundamentais, de modo que exige determinado grau de coordenação e integração entre os mesmos. (STARFIELD, 2002),

Como atributos derivativos, os serviços devem voltar-se, segundo Starfield (2002), para: a) Centralização na família: reconhecimento dos usuários dentro de seus ambientes, de modo que considera o contexto e a dinâmica familiar no âmbito das ações realizadas; b) Competência cultural: envolve o reconhecimento de diferentes necessidades das populações, considerando características étnicas, raciais e culturais; c) Orientação para a comunidade: pressupõe o reconhecimento das necessidades de saúde no contexto social em que vive os usuários, as características de saúde da comunidade e dos recursos nela disponíveis.

No processo de avaliação da orientação para a comunidade, a autora supracitada aponta três tipos de informações: conhecimento das necessidades de saúde da comunidade; informação sobre quanto os profissionais se envolvem nos assuntos da comunidade (inclui o conhecimento das redes sociais e dos sistemas de apoio Serv. Soc. \& Saúde, Campinas, SP v. 12, n 1 (15), p. 9-30 jan./jun. 2013 ISSN 1676-6806 
disponíveis, incluindo recursos recreacionais, religiosos, políticos ou filantrópicos); e, por último, quanto o profissional envolve a comunidade em questões relacionadas à prática (oferta de serviços à comunidade ou aos usuários, pesquisas de satisfação e propostas para qualificar os serviços). Com relação ao alcance da atenção primária orientada para a comunidade, a autora ressalta a importante tentativa realizada por um médico, na Grã-Bretanha, ao assumir responsabilidades pela comunidade, além das funções clínicas, base para o conceito de médico geral comunitário, como um "novo tipo de médico que está engajado na democracia participativa local na busca da maximização da saúde” (HART, 1983, apud STARFIELD, 2002, p. 542) .

Também ressalta outras tentativas, entre elas, as novas maneiras de interação entre organizações clínicas, com a comunidade, pelo Grupo Cooperativo de Saúde de Puget Sound, em Washington, e no Canadá, com ênfase na província do Québec, no esforço de envolver a comunidade em todos os níveis de tomada de decisões. Ainda coloca os esforços na formação de médicos de família em Cuba e de médicos com orientação comunitária, citando como exemplo o México, a Costa Rica e Nicaraguá. (STARFIELD, 2002)

Quanto à capacidade dos sistemas de serviços de saúde, no que tange à sua administração, a autora mostra que as abordagens variam em três tipos principais (SALTMAN, 1994, apud STARFIELD, 2002): controle, escolha e persuasão moral/legal. O controle político condiz com a decisão coletiva, de caráter mais democrático, por meio da participação das pessoas nos orçamentos e alocação de recursos; a escolha, colocada como forma alternativa de administração, baseia-se na autonomia das pessoas escolherem onde e de quem desejam receber seus serviços; e, por último, tem-se o mecanismo de persuasão, representado por sistemas de reparação legal e social por serviços prejudiciais, não proporcionando às pessoas a possibilidade de mudar aspectos relacionados aos serviços que são considerados inadequados.

A análise das reformas orientadas pela APS em países da União Europeia, pelo Observatório Europeu de Sistemas e Políticas de Saúde, a partir de 1990, e publicado no

\footnotetext{
9 “Na Grã-Bretanha, a responsabilidade pelas funções da comunidade era, até pouco tempo, assumida por uma equipe de especialistas em medicina comunitária. Mant e Anderson propuseram que as funções fossem assumidas pelo profissional de atenção primária, com a transferência dos recursos da estrutura atual de medicina comunitária para as unidades de atenção primária; esta transferência tem ocorrido desde os anos 90 (STARFIELD, 2002, p. 543).

Serv. Soc. \& Saúde, Campinas, SP v. 12, n 1 (15), p. 9-30 jan./jun. 2013 ISSN 1676-6806
} 
Brasil em 2010 pelo MS/OPAS/OMS: Atenção Primária Conduzindo as Redes de Atenção à Saúde: Reforma Organizacional na Atenção Primária Europeia, os países europeus destacam-se pela garantia de acesso das populações aos serviços de saúde, por meio de modelos de proteção social via seguros de saúde ou de serviços nacionais de saúde. De maneira geral, é crescente o papel da atenção primária, principalmente pela transferência de cuidados hospitalares para o nível ambulatorial, com diversidade nas configurações institucionais, na organização e prestação de serviços.

O referido estudo evidencia as diferentes concepções de atenção primária no atual contexto europeu, não sendo esta facilmente conceituada sem a Medicina de Família e Comunidade, de modo que tem sido adotada uma categoria intermediária, denominada de atenção primária estendida. Essa perspectiva, mais abrangente do que a Medicina de Família e Comunidade, coloca o centro do desenvolvimento da atenção primária existente em muitos países como ponto fundamental dos esforços para melhorar a coerência e a coordenação da prestação de serviços de atenção à saúde. (BRASIL, 2010b)

Conill (2008) observa que as funções da APS adotadas pelo Observatório Europeu praticamente coincidem com os atributos sugeridos por Starfield (2002), para avaliar essas práticas, com destaque para: primeiro contato, longitudinalidade, integralidade, coordenação, centralização na família, orientação para a comunidade.

O fortalecimento desse nível de atenção, na Europa, também é observado por Giovanella e Mendonça (2008), principalmente nas funções de coordenação e primeiro contato, a partir da década de 1990. Para as autoras, a ênfase é colocada na assistência clínica e nos cuidados individuais, de modo que não contempla aspectos da concepção abrangente da APS, voltada para problemas coletivos, atuação intersetorial e participação social nos serviços de saúde.

Contudo, os estudos mencionados demonstram que a APS é compreendida e implementada, em diferentes dimensões, em perspectiva mais ou menos abrangente, mais ou menos seletiva e focalizada, como estratégia de reorganização do primeiro nível de atenção ou como estratégia de reorganização de sistemas de saúde. A opção por uma ou outra perpassa, dentre outros aspectos, diferentes formas de organização e modelos dos sistemas de saúde, pela correlação de forças existentes e pelas condições sóciohistóricas de cada momento, de modo que poderá ou não contribuir para o fortalecimento do processo de democratização da saúde. 
Dos atributos e funções da APS contidos nos estudos de Starfield (2002) e do Observatório Europeu de Sistemas e Políticas de Saúde (2010), pode-se dizer que há valorização do vínculo entre equipe de saúde (com ênfase no profissional médico) e população/usuário. O centro da discussão coloca-se principalmente na atenção clínica, em abordagem mais ampliada, com valorização do primeiro atendimento, numa atenção longitudinal e coordenada, com centralidades familiar e comunitária. A autonomia do usuário na decisão relacionada à utilização dos serviços, na aceitação das orientações e recomendações pelos profissionais de saúde e na decisão de quanto querem participar nesse processo, também são pontos elencados.

No âmbito da atenção à saúde, consideram-se esses atributos relevantes e necessários. No entanto, quando descolados de perspectiva sócio - crítica presente na produção social da saúde, aponta para uma tendência individualizante, despolitizada, que tende para o fortalecimento da subalternização do usuário e no simples assentimento deste nas decisões profissionais.

Outro ponto importante nos estudos refere-se à orientação para a comunidade. Apesar do pouco alcance das experiências, segundo Starfield (2002), esse atributo voltase para a participação da comunidade nas decisões sobre sua saúde e para quanto a equipe conhece as necessidades de saúde no contexto social vivido. No entanto, a autora ressalta que, apesar do direcionamento da Conferência de Alma-Ata para orientação à comunidade, tal atributo ainda não é uma realidade, na medida em que faltam evidências de sua prática, um importante desafio para os sistemas de atenção primária. O sentido da participação da comunidade expresso também tende à individualização e despolitização da participação, uma vez que se volta para uma perspectiva cooperativa e adesista na relação profissional de saúde e usuários, de tal modo que o envolvimento da comunidade está relacionado à prática e às decisões de sua saúde.

\section{A Renovação da Atenção Primária em Saúde nas Américas: Participação Sintonizada com os Interesses Governamentais}

O não cumprimento da meta de "saúde para todos no ano 2000”, associado às estratégias para cumprimento dos objetivos de Desenvolvimento do Milênio, tem motivado o posicionamento de organismos internacionais como a OMS e a OPAS. Serv. Soc. \& Saúde, Campinas, SP v. 12, n 1 (15), p. 9-30 jan./jun. 2013 ISSN 1676-6806 
Ambos os organismos reafirmam a necessidade de Renovação da Atenção Primária em Saúde nas Américas ${ }^{10}$, sob o argumento de que a APS é parte integrante do desenvolvimento de sistemas de saúde e que esses sistemas, com base na APS, têm a melhor abordagem para o alcance de melhorias sustentáveis e equitativas na saúde das populações das Américas (OPAS/OMS, 2008).

No documento, a OPAS/OMS (2008) coloca-se como defensora de um sistema de saúde, com base na APS, com enfoque abrangente na organização e operacionalização, tendo como fundamento três valores centrais, a saber:

a) Direito ao mais alto nível possível de saúde: implica os direitos legais dos cidadãos e das responsabilidades do governo e de outros atores, com responsabilização no sistema de saúde, sendo a APS orientada à qualidade, eficiência e eficácia.

b) A equidade na saúde: colocada como valor intrínseco, capaz de corrigir as iniquidades, por meio do exercício de suas reivindicações morais e legais à saúde e outros direitos sociais. Volta-se para o combate das diferenças injustas no estado de saúde, no acesso aos cuidados e ambientes de melhoria da saúde e no tratamento dentro do sistema de saúde e de serviços sociais.

c) Solidariedade: colocada como forma de manifestação dos governos nacional e local, na formação de organizações voluntárias e sindicatos, e em outras formas de participação dos cidadãos na vida cívica. A solidariedade social nos sistemas de saúde, com base na APS, é defendida como exigência para que os investimentos em saúde sejam sustentáveis, ofereçam proteção financeira e que permitam que o setor de saúde trabalhe com sucesso com outros setores e atores, cuja participação é necessária tanto para melhorar a saúde como as condições que ajudam a determiná-la.

O documento estabelece que os sistemas de saúde baseados na APS são fundamentados em princípios que fornecem o suporte para políticas de saúde, legislação, critérios de avaliação, geração e alocação de recursos e operação do sistema de saúde (OPAS/OMS, 2008):

\footnotetext{
${ }^{10}$ Documento publicado no Brasil em 2008, pela OPAS/OMS.

Serv. Soc. \& Saúde, Campinas, SP v. 12, n 1 (15), p. 9-30 jan./jun. 2013 ISSN 1676-6806
} 
a) Capacidade em responder às necessidades de saúde das pessoas: estabelece que os sistemas de saúde sejam centrados em pessoas, tendo como fundamento a abordagem de atender às necessidades de saúde definidas objetivamente pelos especialistas e padrões acordados, ou subjetivamente, a partir das necessidades observadas pelo indivíduo ou pela população.

b) Os serviços orientados à qualidade: implica tratar todas as pessoas com dignidade e respeito, enquanto asseguram o melhor cuidado possível para seus problemas de saúde, de modo que requer procedimentos para avaliar a eficiência e a eficácia de intervenções preventivas e curativas de saúde e de designar os recursos adequadamente.

c) A responsabilização governamental: refere que, na garantia de direitos ao cidadão, se fazem necessários políticas e procedimentos legais e regulatórios, que permitam aos cidadãos exigir seus direitos, caso não sejam atendidos. Para tanto, se fazem necessário o monitoramento e a qualificação contínua e permanente do sistema de saúde, de forma transparente, e sujeito ao controle social.

d) Justiça social: propõe que as ações governamentais sejam avaliadas pelo quanto garantem o bem-estar de todos os cidadãos, de modo especial os mais vulneráveis, garantindo justiça social, a partir de algumas abordagens, dentre elas, a de melhorar a educação e as iniciativas inclusivas para a compreensão, pelos cidadãos, de seus direitos, e a de garantir a participação ativa deles no planejamento e na fiscalização do sistema de saúde.

e) Sustentabilidade do sistema de saúde: propõe o estabelecimento de mecanismos para garantir o financiamento adequado, mesmo em períodos de instabilidade, ou mudanças políticas em sistemas de saúde liderados pela APS.

f) Participação: colocada como forma de as pessoas tornarem-se parceiras ativas na tomada de decisões sobre recursos, definição de prioridades e garantia de responsabilização. No nível individual, as pessoas devem estar aptas a tomar decisões livres e plenamente informadas acerca de sua própria saúde e de suas famílias, em um espírito de autodeterminação e confiança. No nível da sociedade, tomar parte na saúde é uma faceta da participação cívica geral; 
garante que o sistema de saúde reflita valores sociais e fornece um meio de controle social de ações públicas e privadas que causam impacto na sociedade.

g) Intersetorialidade: significa que o sistema de saúde deve trabalhar com setores e atores diferentes para impactar os determinantes da saúde, contribuir para atividades de desenvolvimento humano e atingir seu potencial de equidade.

A OPAS/OMS, no documento sobre a renovação da atenção primária, ainda estabelece elementos estruturais e funcionais, interconectados e de ação simultânea, em todos os níveis do sistema de saúde. Os elementos centrais de um sistema de saúde, com base na APS, são os seguintes: cobertura e acesso universais; primeiro contato; atenção integral, integrada e contínua; ênfase na prevenção e promoção; orientações familiar e comunitária; atenção apropriada; organização e gestão ótimas; mecanismos de participação ativa; recursos humanos apropriados; marcos político, legal e institucional sólidos; políticas e programas pró-equidade; recursos adequados e sustentáveis; ações intersetoriais (OPAS/OMS, 2008).

Observa-se que alguns desses princípios e elementos coincidem com atributos sugeridos por Starfield (2002) e com as funções adotadas pelo Observatório Europeu, com destaque para a centralidade na família e comunidade, no primeiro contato, na responsabilização governamental (coordenação), nos mecanismos de participação ativa (orientação para a comunidade).

Considera-se relevante a ênfase em princípios e elementos estruturais e funcionais, voltados para a qualidade dos serviços, intersetorialidade, cobertura e o acesso universal; às atenções integral, integrada e contínua; à ênfase na prevenção e promoção; às orientações familiar e comunitária; aos recursos humanos apropriados; aos marcos político, legal e institucional sólidos.

No entanto, carece de posicionamento a respeito da mercantilização da saúde. Aborda a sustentabilidade do sistema de saúde como um dos princípios, mas não adentra em questões cruciais na atual conjuntura, que inviabiliza o direito humano à saúde, e a consolidação dos princípios que o próprio documento preconiza, principalmente em países subdesenvolvidos.

Se, na Declaração de Alma-Ata, faltou posicionamento mais explícito no que se refere à conjuntura econômica, com a inter-relação entre a política de saúde e a política econômica, o documento de posicionamento da OPAS/OMS, de Renovação da Atenção Primária em Saúde nas Américas, "ratifica a ordem econômica social vigente e delega Serv. Soc. \& Saúde, Campinas, SP v. 12, n 1 (15), p. 9-30 jan./jun. 2013 ISSN 1676-6806 
unicamente para o espaço da política a tarefa de viabilizar políticas de saúde universais” (GÖTTEMS; PIRES, 2009, p. 188).

O não cumprimento da meta de “saúde para todos no ano 2000" e as necessidades de estratégias para cumprimento dos Objetivos de Desenvolvimento do Milênio, no posicionamento da OPAS/OMS de Renovação da Atenção Primária, é colocado de forma descolada da ordem econômica mundial, do processo crescente de mercantilização da saúde, privatização e precarização das condições de vida e trabalho, que a fortalece como mercadoria e inviabiliza o direito universal à saúde, principalmente em países subdesenvolvidos, onde o acesso e a garantia à saúde estão muito distantes do cotidiano de milhares de cidadãos.

Nos valores definidos no documento, o direito à saúde implica a responsabilização dos governos e de outros atores, sobressaindo a equidade, como um dos valores centrais. Se o enfoque atribuído for relacionado à participação, como a possibilidade de parcerias ativas na tomada de decisões sobre recursos, definição de prioridades e garantia de responsabilização, tem-se vinculada a participação como ideia de eficiência, para controle e garantia da equidade sobre os gastos públicos.

Há um alinhamento da perspectiva da APS, no documento, a uma ideia de participação instrumental, voltada principalmente para ações individuais no cuidado de sua própria saúde, na redução de custos, fiscalização e no planejamento.

As reflexões de Jara (2006) sobre os princípios e mecanismos da participação cidadã institucionalizada nas Constituições, na América Latina, indicam importante contribuição na relação participação-eficiência, ao levantar como pontos centrais desse debate duas ideias que dão sentido à participação: a legitimidade e eficiência. É comum a compreensão de que todo poder reside nos cidadãos que o exercem diretamente, ou por meio da representação. Tal afirmativa associa participação e legitimidade, tanto do sistema representativo (legitimidade dos governos por terem sido eleitos pelo povo e por representá-los), como do participativo (quando os cidadãos propõem e revogam leis específicas, por meio de democracia direita). Com a ideia de legitimidade, encontra-se a ideia de eficiência.

A participação colabora para melhorar a eficiência e eficácia das políticas, otimizando os recursos públicos escassos, entregando informação e valoração aos que tomam as decisões e fortalecendo o seu controle. Aqui, os princípios e mecanismos, sobretudo no que se 
refere a organismos territoriais, tendem a associar-se à descentralização ou modernização do Estado e não à ação política dos cidadãos participantes (JARA, 2006, p. 359).

O autor acrescenta que as ideias de inovação democrática, por meio da participação, são complexas, e podem limitar-se à mera cooperação entre sujeitos e governo, deixando o espaço de conflito e disputa de projetos alternativos apenas para a esfera do partido político. Por outro lado, o aspecto político da participação, contido nas Constituições na América Latina e por ele analisadas, pode ser tentativa para que o exercício do poder e da política não seja monopolizado pelos partidos políticos. De modo que há diferentes justificativas na inclusão de mecanismos de participação, a exemplo do Brasil, na Constituição Federal de 1988, de justificação democrática (para ampliar a participação dos cidadãos nas questões públicas), como forma antipolítica; para sobrepor-se à politicagem e corrupção, a exemplo dos casos equatoriano, peruano e venezuelano (JARA, 2006).

E, ainda, segundo Jara (2006), uma terceira versão, vinculada à evolução da participação nos organismos de créditos internacionais, com matriz liberal, limitando-a para a eficiência, colaboração das populações empobrecidas (na informação e no trabalho), de modo a restringir a tomada de decisão conjunta.

A OPAS/OMS, ao posicionar-se pela Renovação da Atenção Primária em Saúde nas Américas, atribui à participação coletiva uma perspectiva ativa, para garantir transparência e responsabilização nos diferentes níveis de atenção; estimular a capacidade das comunidades como parceiros ativos no estabelecimento de prioridades na gestão, avaliação e regulação do setor de saúde e, no campo individual, para que os indivíduos gerenciem melhor sua própria saúde. A participação, seja por meio de ações individuais ou coletivas, deve voltar-se para a promoção de ambientes e estilos de vida saudáveis (OPAS/OMS, 2008).

Reforça o sentido individualizante e despolitizante da participação, com foco nas funcionalidades para o autocuidado, o controle da qualidade dos serviços, com centralidade para a garantia da eficiência na prestação dos serviços, sendo atribuída à população a condição de parceira, despida dos conflitos de classes e de projetos societários que perpassam tais relações.

Assim, a perspectiva de participação da sociedade, no documento, caminha numa lógica cooperativa, no que se refere à saúde individual, funcional, aos interesses da própria equipe e dos órgãos governamentais. A participação ativa alinha-se à ideia de 
eficiência, reforçando mais os interesses governamentais do que garantindo uma ação política dos diferentes sujeitos no processo de democratização da saúde.

\section{CONSIDERAÇÕES FINAIS}

No transcorrer deste artigo, tratou-se da participação em saúde na APS, na tentativa de analisar suas expressões e tendências, assim como seus limites e possibilidades.

Observou-se que, de maneira geral, prevalece a perspectiva instrumental da participação em saúde na APS, voltada principalmente para ações individuais centradas no autocuidado, na redução de custos, na fiscalização e no planejamento.

Assim, há certo alinhamento na concepção de participação de forma instrumental nos atributos sugeridos por Starfield (2002), com as funções adotadas pelo Observatório Europeu e com o posicionamento da OPAS/OMS de Renovação da Atenção Primária em Saúde nas Américas, com destaque para a centralidade na família e comunidade, no primeiro contato, nos mecanismos de participação ativa (orientação para a comunidade), expresso nas seguintes tendências identificadas:

- Participação individual: volta-se para a autonomia do usuário na decisão relacionada à utilização dos serviços, na aceitação das orientações e recomendações pelos profissionais de saúde e na decisão de quanto querem participar nesse processo, numa relação entre equipe de saúde (com ênfase no profissional médico) e população/usuário. O centro da discussão coloca-se principalmente na atenção clínica, em abordagem mais ampliada, a inovação se coloca para a garantia da autonomia do sujeito com a equipe de saúde.

- Participação da comunidade: de caráter coletivo, a participação aparece revestida em uma perspectiva cooperativa e adesista na relação profissional de saúde e usuários, de modo que o envolvimento da comunidade está relacionado à prática e às decisões de sua saúde e, em instâncias mais aprofundadas na responsabilização pela sua própria saúde. No entanto, esse tipo de participação, segundo os documentos analisados, requer que a equipe conheça as necessidades de saúde no contexto social em que vivem Serv. Soc. \& Saúde, Campinas, SP v. 12, n 1 (15), p. 9-30 jan./jun. 2013 ISSN 1676-6806 
os usuários; as características de saúde da comunidade; e os recursos nela disponíveis. Tais requisitos podem abrir possibilidades de trabalho da equipe de saúde e população local, que venham contribuir na organização sócio - política dos sujeitos locais em torno do processo de democratização da saúde, numa perspectiva de participação sócio - critica.

- Participação como ideias de parcerias ativas (ênfase na gestão): no posicionamento da OPAS/OMS de Renovação da Atenção Primária em Saúde nas Américas, aparece a ideia de participação como possibilidade de "parcerias ativas" na tomada de decisões sobre recursos, definição de prioridades e responsabilização, na fiscalização e no planejamento, assim como o caráter da vinculação da participação como ideia de eficiência, para controle e garantia da equidade sobre os gastos públicos. Em tal tendência, encontra-se a perspectiva da participação cidadã/social, por meio de canais específicos, a exemplo dos conselhos locais de saúde.

A preocupação com participação ativa se coloca diante da forma desprovida de sentido ético-político expresso no documento analisado, que tende a alinhar-se à ideia de eficiência, reforçando mais os interesses governamentais do que garantindo uma ação política dos diferentes sujeitos no processo de democratização da saúde, pois é atribuída à população a condição de parceira, despida dos conflitos de classes e de projetos societários que perpassam tais relações.

Contudo, a participação em saúde é inexpressiva na APS, e as propostas evidenciadas nos documentos e referências analisadas, a direcionam para uma participação de caráter instrumental, com forte tendência à despolitização e ausência de sentido político-crítico.

A participação em saúde na APS não deve sobrepor-se ou dissociar-se de outras estratégias de participação e de lutas coletivas, diante das múltiplas determinações da totalidade social, sob o risco de ocultar o mau funcionamento dos serviços, a desresponsabilização estatal, a escassez de recursos e reatualização da responsabilização e culpabilidade individual e familiar da saúde dos indivíduos. Qualquer que seja a modalidade participativa, deve estar entrelaçada à dimensão política, de modo a contribuir no acúmulo para a politização das relações sociais e aprofundamento da democracia.

A (re)constituição dos espaços participativos com conteúdos ético-políticos, a exemplo da APS, quando combinada a outras lutas populares, de organização e mobilização em torno da defesa e expansão da democracia, por si só, não tem Serv. Soc. \& Saúde, Campinas, SP v. 12, n 1 (15), p. 9-30 jan./jun. 2013 ISSN 1676-6806 
capacidade de transformação, mas pode somar-se à luta coletiva por novos padrões de civilidade e novas formas de sociabilidade, na direção da emancipação humana.

\section{REFERÊNCIAS}

ANDERSON, P. Balanço do neoliberalismo. In: SADER, E.; GENTILI, P. (Org.) Pósneoliberalismo: as políticas sociais e o estado democrático. Rio de Janeiro: Paz e Terra, 1995. p. 9-23.

BRASIL. Conselho Nacional de Secretários de Saúde. Atenção primária e promoção da saúde. Brasília: CONASS, 2011. Coleção para Entender a Gestão do SUS, v. 3.

BRASIL. Ministério da saúde. Diretrizes do NASF: núcleo de apoio à saúde da família. Série A. Normas e Manuais Técnicos. Caderno de Atenção Básica, n. 27, 2010. BRASIL. Ministério da Saúde. Secretaria de Vigilância em Saúde/ Organização Panamericana da Saúde/Organização Mundial da Saúde/ Observatório Europeu de Sistemas e Políticas de Saúde. Atenção primária conduzindo as redes de atenção à saúde: Reforma organizacional na atenção primária europeia. Tradução e impressão, 2010b. CAMPOS, G. W. de S. O SUS entre a tradição dos sistemas nacionais e o modo liberalprivado para organizar o cuidado à saúde. Ciência \& Saúde Coletiva, 12 (Sup), 2007. CONFERÊNCIA INTERNACIONAL SOBRE CUIDADOS PRIMÁRIOS DE SAÚDE. Declaração de Alma-Ata. Alma-Ata, 1978. Disponível em: <http://www.opas.org.br/coletiva/uploadArq/Alma-Ata.pdf>. Acesso em: 12 set. 2011. CONILL, E. M. Ensaio histórico-conceitual sobre a atenção primária à saúde: desafios para a organização de serviços básicos e da estratégia saúde da família em centros urbanos no Brasil. Caderno de Saúde Pública, v. 24, supl.1, Rio de Janeiro, 2008.

CORTES, S. M. V. As origens da ideia de participação na área de saúde. Saúde em Debate, n. 51, Londrina, Paraná, jun. 1996.

GIOVANELLA, L.; MENDONÇA, M. H. G. Atenção primária à saúde. In: GIOVAnella, L. et al. (Orgs.). Políticas e sistemas de saúde no Brasil. Rio de Janeiro: Fiocruz, 2008. 
GÖTTEMS, L. B. D. et al. Trajetória da política de atenção básica à saúde no Distrito federal, Brasil (1960 a 2007): análise a partir do marco teórico do neo-institucionalismo histórico. Cadernos de Saúde Pública, v. 25, n. 6, Rio de Janeiro, jun. 2009.

PIRES, M. R. G. M. Para além da atenção básica: reorganização do SUS por meio da interseção do setor político com o econômico. Rev. Saúde e Sociedade. São Paulo, v. 18, n. 2, p.189-198, 2009.

IAMAMOTO, M. V. Serviço Social em tempo de capital fetiche: capital financeiro. Trabalho e questão social. São Paulo: Cortez, 2008.

JARA, F. H. de La. A institucionalização da participação cidadã: análise dos marcos legais da participação na América Latina. In: DAGNINO, E.; OLVERA, A.; PANFICHI, A. A disputa pela construção democrática na América Latina. São Paulo: Paz e Terra, Campinas: Unicamp, 2006.

MENDES, E. V. Uma agenda para a saúde. São Paulo: Hucitec, 1996.

MENDES, E. V. As redes de atenção à saúde. Brasília: OPAS/CONASS, 2011.

ORGANIZAÇÃO PAN-AMERICANA DA SAÚDE (OPAS). Renovação da atenção primária em saúde nas Américas. Documento de Posicionamento da Organização Pan-americana da Saúde/OMS. Washington, 2007 (em inglês), publicação em português, 2008. Disponível em: <http://www.opas.org.br/servico/arquivos/Sala5575.pdf>. Acesso em: 20 set. 2011.

STARFIELD, B. Atenção primária: equilíbrio entre necessidades de saúde, serviços e tecnologia. Brasília: Unesco, Ministério da Saúde, 2002. 726p.

PAIM, J. S. Modelos de atenção à saúde no Brasil. In: GIOVANELLA, L. et al. (Org.). Políticas e sistemas de saúde no Brasil. Rio de Janeiro: Fiocruz, 2008. 